|| ISSN(online): 2589-8698 || ISSN(print): 2589-868X ||

International Journal of Medical and Biomedical Studies

Available Online at www.ijmbs.info

NLM (National Library of Medicine ID: 101738825)

Index Copernicus Value 2019: 79.34

Original Research Article

Volume 5, Issue 8; August: 2021; Page No. 199-200

\title{
TO STUDY THE EPIDEMIOLOGICAL PROFILE OF PITYRIASIS ROSEA
}

\section{Dr. Ashok Kumar ${ }^{1}$, Dr. B.C. Ghiya ${ }^{2}$, Dr. Prasoon Soni ${ }^{3}$, Dr. R. D. Mehta ${ }^{4}$}

${ }^{1}$ Junior Specialist, Department of Dermatology, Venereology and Leprosy, Govt. S K Hospital Sikar (Rajasthan)

${ }^{2-4}$ Department of Dermatology, Venereology and Leprosy, S.P. Medical College and PBM \& Associated Group of Hospitals, Bikaner

Article Info: Received 19 June 2021; Accepted 08 August 2021

DOI: https://doi.org/10.32553/ijmbs.v5i8.2110

Corresponding author: Dr. Ashok Kumar

Conflict of interest: No conflict of interest.

\section{Abstract}

Background: Pityriasis rosea (PR) is an acute inflammatory skin disorder. Though self-limiting but the bothersome symptoms often have a significant impact on the quality-of-life of patients. To study the epidemiological profile of pityriasis rosea.

Methods: A prospective controlled study was conducted on 60 patients of pityriasis rosea attending outdoor patient department of Dermatology, Venereology and Leprosy, SP Medical College and PBM Hospital, Bikaner.

Results: Mean age of patients in study group was $21.26 \pm 10.19$ years. 39 patients were female and 21 patients were male. Acute onset of disease was present in $88.30 \%$ of patients. Mother patch was present in $40 \%$ patients.

Conclusion: We concluded from the present study that pityriasis rosea is common in 20-30 years age group with male predominance.

Keywords: Pityriasis rosea (PR), Clinical profile, Skin disorder.

\section{Introduction}

Pityriasis rosea (PR) is an acute inflammatory skin disorder. Though self-limiting but the bothersome symptoms often have a significant impact on the quality-of-life of patients. The incidence of PR varies from 0.39 to $4.80 / 100$ dermatological patients ${ }^{1,2}$. The association of human herpes virus 6 (HHV-6) and HHV-7 with PR suggest that antiviral agents can be tried to speed up recovery of $\mathrm{PR}^{3}$. Till date, supportive care with topical emollients and antihistamines is practiced by dermatologists for this disorder. Oral erythromycin was once reported to be of benefit to patients with $\mathrm{PR}^{4}$, but recent clinical experiences suggest that the use of macrolides may not be useful in the treatment of $\mathrm{PR}^{5,6}$. Studies evaluating acyclovir in $\mathrm{PR}$ are being conducted worldwide, however, data on Indian patients is scarce $^{3}$

\section{Material and Methods}

A prospective controlled study was conducted on 60 patients of pityriasis rosea attending outdoor patient department of Dermatology, Venereology and Leprosy, SP Medical College and PBM Hospital, Bikaner. The cases were diagnosed on the basis of typical clinical presentation. These patients were randomly divided into two groups of 30 each in group A (Study group) and group B (Control group). Group A was receive oral Acyclovir $800 \mathrm{mg}$ five times a day for 7 days and Cetirizene $10 \mathrm{mg}$ at night, topically Calamine lotion or Glycerine lotion till the symptomatic relief and group B was receive Cetirizene $10 \mathrm{mg}$ in the night, topically Calamine lotion or Glycerine lotion till the symptomatic relief. PATIENTS SELECTION CRITERIA

Patients were selected or excluded on the basis of following criteria.

\section{INCLUSION CRETERIA}

1. All patients more than 12 years of age.

2. Clinical proven cases of Pityriasis rosea.

3. New and relapsing cases of Pityriasis rosea.

\section{EXCLUSION CRETERIA}

1. All patients with renal disease.

2. Patients with unpredictable behavior, who cannot be followed up.

3. Pregnancy and lactation.

\section{Diagnosis}

The patients were diagnosed on the basis of typical clinical features: a single, isolated oval scaly pink maculae or patch (the "herald" or "mother patch") on the body, particularly on the trunk, upper arms, neck or thighs.

Characteristic orientation of the discrete circular or oval lesions along lines of skin cleavages, parallel to the ribs with peripheral collarette scaling with central clearance on at least two lesions

\section{Observations}


Table1: General characteristics of patients

\begin{tabular}{|l|l|l|}
\hline \multicolumn{2}{|l|}{ Mean age } & $21.26 \pm 10.19$ Yrs \\
\hline Female : Male & Acute & $21: 39$ \\
\cline { 2 - 3 } Onset & Gradual & $53(88.30 \%)$ \\
\cline { 2 - 3 } & Insidious & $6(10.00 \%)$ \\
\hline \multirow{2}{*}{ Mother patch present } & Yes & $1(1.70 \%)$ \\
\cline { 2 - 3 } & No & $24(40.00 \%)$ \\
\hline
\end{tabular}

Mean age of patients in study group was $21.26 \pm 10.19$ years. 39 patients were female and 21 patients were male. Acute onset of disease was present in $88.30 \%$ of patients. Mother patch was present in $40 \%$ patients.

\section{Discussion}

Mean age of patients in study group was $21.26 \pm 10.19$ years. 39 patients were female and 21 patients were male. Acute onset of disease was present in $88.30 \%$ of patients. Mother patch was present in $40 \%$ patients. Majority of the cases of PR reported between the ages of 10 and 35 years. ${ }^{7,8}$ Our study findings are comparable with other studies with respect to peak age of incidence. , $^{9,10}$

The overall male-to-female ratio is $1: 1.86{ }^{8}$ However, our study has shown a male preponderance. Ganguly in a clinic epidemiological study of PR from South India has also reported a male preponderance. ${ }^{11}$

\section{Conclusion}

We concluded from the present study that pityriasis rosea is common in 20-30 years age group with male predominance.

\section{References}

1. de Souza Sittart JA, Tayah M, Soares Z. Incidence pityriasis rosea of Gibert in the Dermatology Service of the Hospital do Servidor Público in the state of São Paulo. Med Cutan Ibero Lat Am 1984; 12:336-8.

2. Olumide Y. Pityriasis rosea in Lagos. Int J Dermatol 1987; 26:234-236.

3. Drago F, Vecchio F, Rebora A. Use of high-dose acyclovir in pityriasis rosea. J Am Acad Dermatol 2006; 54:82-85.
4. Sharma PK, Yadav TP, Gautam RK, Taneja N, Satyanarayana L. Erythromycin in pityriasis rosea: A double-blind, placebo-controlled clinical trial. J Am Acad Dermatol 2000; 42:241-4.

5. Bukhari IA. Oral erythromycin is ineffective in the treatment of pityriasis rosea. J Drugs Dermatol 2008; 7:625.

6. Amer A, Fischer H. Azithromycin does not cure pityriasis rosea. Pediatr 2006; 117:1702-5.

7. Bjomberg A, Hellgren L. Pityriasis Rosea: A statistical, clinical and laboratory investigation of 826 patients and matched healthy controls. Acta Derm Venereol. 1962;42(Suppl 50):1-68.

8. Chauang TY, Perry HO. Pityriasis Rosea in Rochester, Minmesota, 1969-1978:A 10 year epidemiologic study. J Am Acad Dermatol. 1982;7:80-9.

9. Niles HD, Klump MM. Pityriasis Rosea: Review of literature and report of two hundred and nineteen cases in thirty eight of which convalescent serum was used. Arch Dermatol Syph. 1940;41:265-94.

10. Cohen EL. A clinical study of 206 cases of Pityriasis Rosea. Br J Dermatol. 1967;79:533-7.

11. Ganguly S. A clinicoepidemiological study of pityriasis rosea in South India. Skinmed. 2013;11:141-6. 